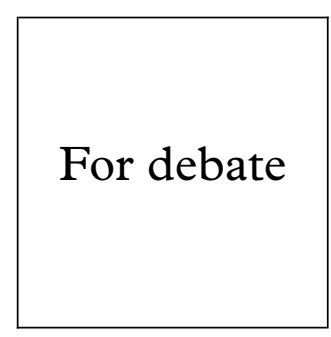

\title{
Genital herpes: Heisenberg revisited
}

\author{
David Goldmeier
}

In the confirmation of recurrences of genital herpes, patient defined disease reactivation and virological data hold the scientific high ground. The influence of the psyche on recurrence rates and perception of recurrences has been largely neglected and marginalised up to the present, possibly because research work in that area has been and continues to be of poor calibre. However, neglected psychological variables may render otherwise relevant clinical trials uninterpretable. Psychological aspects of counselling before testing for serum herpes simplex type 2 antibodies are also discussed.

(Sex Transm Inf 1998;74:219-220)

Keywords: genital herpes; Heisenberg; herpes simplex virus

The August 1997 edition of Genitourinary Medicine was a veritable cornucopia for those of us interested in the psychological aspects of genital herpes. However, some of the points raised need further comment and clarification.

Tests for serum antibodies against type 1 and 2 herpes simplex virus will be easy to request in the not too distant future, but their correct usage in the context of the individual patient will take more practice and experience. $\mathrm{Pa}$ tients' attitudes to such a test are important, ${ }^{1}$ but as we have learned over the years with tests to detect HIV, the physician's expertise and opinion based on evidence will need to guide and temper ill thought out patient requests for herpes simplex virus status. Physicians also need to develop a feel for how and when to use these tests. General experience in counselling will be important for healthcare workers to take with them into this new area. Prospective studies using psychosocial baseline and follow up variables should be correlated with the outcome of herpes simplex virus antibody testing. Thus armed, counselling can proceed optimally.

Genital herpes sufferers and healthcare workers have long felt that "stress" is associated with frequent recurrences in otherwise classically immunocompetent people. "Stressors" may mean many things to many people, including internal psychological turmoil and external adverse events. Unfortunately for researchers, stressors rarely occur in isolation, so that other events such as cannabis intake and the friction of intercourse often interact with them to encourage recurrences. ${ }^{3}$ There has been much discussion as to whether psychiatric illness and abnormal personalities increase the rates of recurrence of genital herpes. ${ }^{4-7}$ It is important to remember that these variables do not affect the recurrence rates directly but probably via neurological and hormonal intermediates acting on the immune system. For instance, T lymphocyte response to phytohaemaglutinin and concanavalin $\mathrm{A}$ is reduced in the early weeks after bereavement. ${ }^{8}$ Locke et al have found that natural killer cell activity was low in those subjects reporting anxiety, depression, as well as stressful life events in the recent past. ${ }^{9} \beta$ Adrenergic stimulation, as seen in anxiety, seems overall to depress macrophage and lymphocyte activity. ${ }^{10}$ In spite of such elegant and tantalising studies, the links between psychological stress and subtle impairment of the immune system are far from straightforward.

As Green and Kocsis pointed out, ${ }^{11}$ most of the research attempting to link psychosocial variables with rates of recurrences of genital herpes is retrospective. There are, in fact, so many possible such influences that the whole field is similar to Heisenberg's uncertainty principle regarding the position of perinuclear electrons - we know a little about some areas of probability. With the advent of effective, safe antivirals and similar prospects for vaccines, we may never know these interactions in any greater detail. A small number of groups have undertaken prospective studies and show the type of work that can be done, but they need replication. ${ }^{12-16}$ Kemeny and colleagues ${ }^{16}$ measured psychiatric profiles and lymphocytes subset numbers in patients with recurring genital herpes prospectively month by month. In any particular month depressive mood was linked to higher frequencies of recurrences and a reduced proportion of $\mathrm{T}$ lymphocytes in blood (suppressor cytotoxic cells). Cassidy and colleagues $^{17}$ purported to show that noncoping lifestyle and personality is associated with increased frequency of genital herpes. This may well be so. Our own group looked at 50 patients who were aciclovir naive and were worried about their frequently recurrent genital herpes. ${ }^{14}$ The lie score of the Eysenck Personality Questionnaire was significantly higher in this group compared with patients with first attacks.

Eysenck's personality traits are thought to be based on cortical arousal differences in various population subgroups and therefore possibly have reflections in different immunological profiles. The lie score either picks up "fakers" (who possibly fake to themselves or their partners that they don't have genital herpes) or possibly these patients are "socially naive". The latter inductive hypothesis may have some similarities to "non-coping personality".
London W2 1NY

D Goldmeier

Accepted for publication 2 February 1998 
Cassidy and colleagues' paper $^{17}$ is a retrospective analysis. More importantly, it has measured its psychosocial variables on three patient groups which display overt iatrogenic bias. Patients in these groups either received no specific antiherpes treatment, episodic aciclovir, or continuous aciclovir. The latter group's mean natural recurrence rate is thus significantly distorted by treatment. Personality measures that have been validated and found to be reliable should be stable over time. Assessment at recurrences and between recurrences should not give significantly different results. This is not the case for psychiatric illness, particularly anxiety (and to a lesser extent depression) which can vary quite markedly within relatively short spaces of time. Appropriate psychiatric assessment must therefore be prospective and frequent so as to pick up the changes that many patients complain about just before recurrences, whether or not they are caused by cytokine release. Again Kemeny et al have shown the way in this regard.

Lastly, Green and Kocsis ${ }^{11}$ in their review article, and to be truthful ourselves in our earlier studies, ${ }^{13-15}$ have failed to consider pain perception as an important issue. Herpetic lesions may be perceived as painful or painless, as well as a range of unpleasant sensations in between. ${ }^{18} 19$ There is known to be a linear relation between anxiety and pain - thus increased anxiety results in a lowering of the pain threshold. ${ }^{20}$ This is also the case with anxiety trait-for example, Eysenck's "neuroticism" variable. Pain is much more likely to be perceived in a person with a high neuroticism/ high extroversion combination than in a high neuroticism/high introversion personality. ${ }^{21}{ }^{22}$

Other personality traits such as "non-coping style" have not been found to affect pain thresholds. ${ }^{23}$ Furthermore, "learned helplessness", such as continuously unavailable psychological and antiviral support in a situation with frequent recurrences is likely to heighten pain levels. ${ }^{24}$ Continuous aciclovir may result in less frequent as well as less painful recurrences because patients feel in charge of their condition. Much still remains unexplained about the mechanisms of pain perception. The simplistic views of the early physiologists that a "direct line" unidirectional ascending transmission system exists between peripheral nociception and central brain areas has been replaced by complex models in which ascending and descending influences interact. Melzack's gate control theories ${ }^{25}$ in essence hypothesise that other (than pain) sensory fibres from, say, touch receptors and descending pathways from central cortical areas interact to produce the final outcome of pain perception. Thus attention, distraction, mood, expectations, memory, and personality are all given a credible role in pain perception. These insights into pain perception imply that patients cannot be relied upon to report objectively whether or not a recurrence has occurred.

What is being asked of patients and their healthcare workers, very frequent genital examination and tests for viral detection, psychosocial assessment, and immunological examination is a tall order but one that, if undertaken, would yield great insight into the many causes of recurrences of genital herpes.

1 Fairly I, Monteiro EF. Patient attitudes to type specific serological tests in the diagnosis of genital herpes. Genitourin Med 1997;73:259-62.

2 Hutfield DC. Genital herpes. Br F Vener Dis 1968;44:24150

3 Juel-Jenson BE. A new look at infectious diseases. Herpes simplex and zoster. BMF 1973;i:406-10.

4 Vanderplate C, Kerrick G. Stress reduction treatment of severe recurrent genital herpes virus. Biofeedback Self Regulat 1985;10:181-8.

5 Rand K, Hoon E, Massey J, et al. Daily stress and recurrence of genital herpes simplex. Arch Intern Med 1990;150:188993.

6 Hoon EF, Hoon PW, Rand KH, et al. Psychobehavioural model of genital herpes recurrence. $\mathcal{F}$ Psychosom Res 1991; model of gen:

7 Longo DJ, Clum GA. Psychosocial factors affecting genital herpes recurrences. $\mathscr{f}$ Psychosom Res 1989;33:161-6.

8 Bartrop RW, Lazarus L, Luckhurst E, et al. Depressed lymphocyte function after bereavement. Lancet 1977;i:834-6.

9 Locke SE, Hurst MW, William RM, et al. The influence of psychosocial factors on human cell mediated immune function. Presented at the meeting of the American Psychosomatic Society, 1978.

10 Hall RN, Goldstein AL. Neurotransmitters and the immune system. In: Ader R, ed. Psychoneuroimmunology. New York: Academic Press, 1981:521-43.

11 Green J, Kocsis A. Psychological factors in recurrennt genital herpes. Genitourin Med 1997;73:253-8.

12 Goldmeier D, Johnson A. Does psychiatric illness affect the recurrence rate of genital herpes? Br f Vener Dis 1982; 58:40-3.

13 Goldmeier D, Johnson A, Jeffries D, et al. Psychological aspects of recurrences of genital herpes. $\mathcal{F}$ Psychosomatic Res 1986; 30:601-8.

14 Goldmeier D, Johnson A, Byrne M, et al. Psychosocial implications of recurrent genital herpes simplex infection. Genitourin Med 1988;64:327-30

15 Carney O, Ross E, Bunker C, et al. A prospective study of the psychological impact on patients of a first episode of genital herpes. Genitourin Med 1994;70:40-5.

16 Kemeny ME, Cohen F, Zegans LS, et al. Psychological and immunological predictors of genital herpes recurrences. Psychosomatic Med 1989;51:195-208.

17 Cassidy L, Meadows J, Catalán J, et al. Are reported sress and coping style associated with frequent recurrence of and coping style associated with frequent recur

18 Silber TJ, Burgess GR. Painless primary herpes. F Adolescent Health Care 1985;6:40-2.

19 Corey L, Adams HE, Brown VA, et al. Genital herpes simplex virus infection; clinical manifestations, course and complications. Ann Intern Med 1985;98:952-72.

20 Pearse S, Miles A. Chronic pain. In: Granville-Grossman K ed. Recent advances in psychiatry 8. Edinburgh: Churchill Livingstone, 1993:123-42.

21 Bond MR. The relation of pain to the Eysenck Personality Inventory, Cornell Medical Index and Whitely Index of Hypochondriasis. Br F Psychiatry 1971;119:671-8.

22 Bond MR. Personality studies in patients with pain secondary to organic disease. F Psychosomatic Res 1973;179:257-63.

23 Cohen F, Lazarus RS. Active coping processes, coping dispositions and recovery from surgery. Psychosom Med 1973; positions and

24 Pennebaker JW, Burnam MA, Schaeffer MA, et al . Lack of control as a determinant of perceived physical symptoms. $\mathcal{F}$ Pers Soc Psychol 1977:35:167-74.

25 Melzack R. The challenge of pain. Harmondsworth: Penguin Books, 1983. 